\title{
THE ROLE OF BIOTRANSFORMATION ENZYMES IN THE DEVELOPMENT OF RENAL INJURY AND UROTHELIAL CANCER CAUSED BY ARISTOLOCHIC ACID: URGENT QUESTIONS AND DIFFICULT ANSWERS
}

\author{
Marie Stiborova $^{a *}$, Eva Frei ${ }^{\mathrm{b}}$, Volker M. Arlt ${ }^{\mathrm{c}}$, Heinz H. Schmeiser ${ }^{\mathrm{b}}$ \\ a Department of Biochemistry, Faculty of Sciences, Charles University, Albertov 2030, 12840 Prague, Czech Republic \\ ${ }^{b}$ Division of Molecular Toxicology, German Cancer Research Center, Im Neuenheimer Feld 280, 69120 Heidelberg, Ger- \\ many \\ c Section of Molecular Carcinogenesis, Institute of Cancer Research, Sutton, Surrey, SM25NG, United Kingdom
}

Received: January 10, 2009; Accepted: February 3, 2009

Key words: Aristolochic acid/Metabolism/Aristolochic acid nephropathy (AAN)/Balkan endemic nephropathy (BEN)/Renal injury/Urothelial cancer

Background: Ingestion of aristolochic acid (AA) is associated with the development of aristolochic acid nephropathy (AAN), which is characterized by chronic renal failure, tubulointerstitial fibrosis and urothelial cancer. AA may also cause another type of kidney fibrosis with malignant transformation of the urothelium, called Balkan Endemic Nephropathy (BEN). The compound predominantly responsible for the nephropathy and urothelial cancer of AA, is aristolochic acid I (AAI) which is a genotoxic mutagen after metabolic activation The activation pathway involves reduction of the nitro group to a cyclic $N$-acylnitrenium ion that can form covalent DNA adducts. These specific DNA adducts have been detected in experimental animals exposed to AAI, and in urothelial tissues from AAN patients. In rodent tumours induced by AAI, 7-(deoxyadenosin- $N^{6}$-yl)aristolactam I was the most abundant DNA adduct formed and associated with activation of ras oncogenes through a characteristic transversion mutation. Such A:T $\rightarrow$ T:A mutations have been identified in TP53 of urothelial tumour DNA of an AAN patient and in several patients suffering from BEN along with specific AA-DNA adducts. Understanding which enzymes are involved in AAI activation to species forming DNA adducts and/or detoxification to its $O$-demethylated metabolite aristolochic acid Ia (AAIa) is important in order to assess susceptibility to this carcinogen.

Methods and Results: A literature search.

Conclusions: The most important human enzymes activating AAI by simple nitroreduction in vitro are hepatic and renal cytosolic NAD(P)H:quinone oxidoreductase, hepatic microsomal cytochrome P450 (CYP) 1A2 and renal microsomal NADPH:CYP reductase as well as cyclooxygenase which is highly expressed in urothelial tissue. However, the contribution of most of these enzymes to the development of AAN and BEN diseases is still unclear. Hepatic CYP enzymes were found to detoxify AAI to AAIa in mice, and thereby protect the kidney from injury. CYP enzymes of the $1 \mathrm{~A}$ subfamily seem to play a major role in this process in mouse liver. Likewise, among human CYP enzymes, CYP1A1 and 1A2 were found to be the most efficient enzymes participating in AAI oxidation to AAIa in vitro. Nevertheless, which CYPs are the most important in this process in both animal models and in humans have not been entirely resolved as yet. In addition, the relative contribution of enzymes found to activate AAI to species responsible for induction of urothelial cancer in humans remains still to be resolved.

\section{INTRODUCTION}

\section{Aristolochic Acid}

Aristolochic acid (AA), the plant extract of Aristolochia species, is a mixture of structurally related nitrophenanthrene carboxylic acids, with 8-methoxy-6-nitro-phenanthro-(3,4-d)-1,3-dioxolo-5-carboxylic acid (AAI) and 6-nitro-phenanthro-(3,4- $d$ )-1,3-dioxolo-5-carboxylic acid (AAII), being the major components ${ }^{1}$ (Fig. 1). AA is proven to be the cause of so-called Chinese herb nephropathy $(\mathrm{CHN})$, a unique type of rapidly progressive renal fibrosis associated with the prolonged intake of Chinese herbal remedies for slimming, and observed for the first time in Belgium in $1991^{2-4}$. Over $100 \mathrm{CHN}$ cases have been identified so far in Belgium, half of which needed renal replacement therapy, mostly including renal transplantation $^{5}$. The nephrotoxicity has been traced to the ingestion of the herbal preparation Aristolochia fangchi containing nephrotoxic AA inadvertently included in slimming pills ${ }^{3}$. CHN patients, who were exposed to Aristolochia species containing AA and had no relationship with the Belgian slimming clinic in question, have been identified in other European countries, in Asia and in the USA ${ }^{5,6}$. Therefore, this disease is now called aristolochic acid nephropathy (AAN) ${ }^{5-8}$. A high prevalence of urothelial cancer was found in the cohort of AAN patients in Belgium ${ }^{9}$ and cases of urothelial cancer have also been described in other countries ${ }^{10,11}$. These findings highlight the carcinogenic potential of AA to humans. Indeed, AA is among the most potent $2 \%$ of known carcinogens ${ }^{1,5,12}$. As a con- 
<smiles>COc1cccc2c1cc([N+](=O)[O-])c1c(C(=O)O)cc3c(c12)OCO3</smiles>

(AAI)

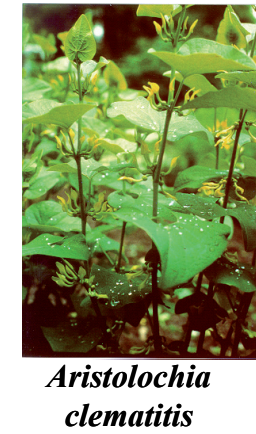

aristolochic acid II

(AAII)

Fig. 1. Chemical structures of aristolochic acid I (AAI) and II (AAII)

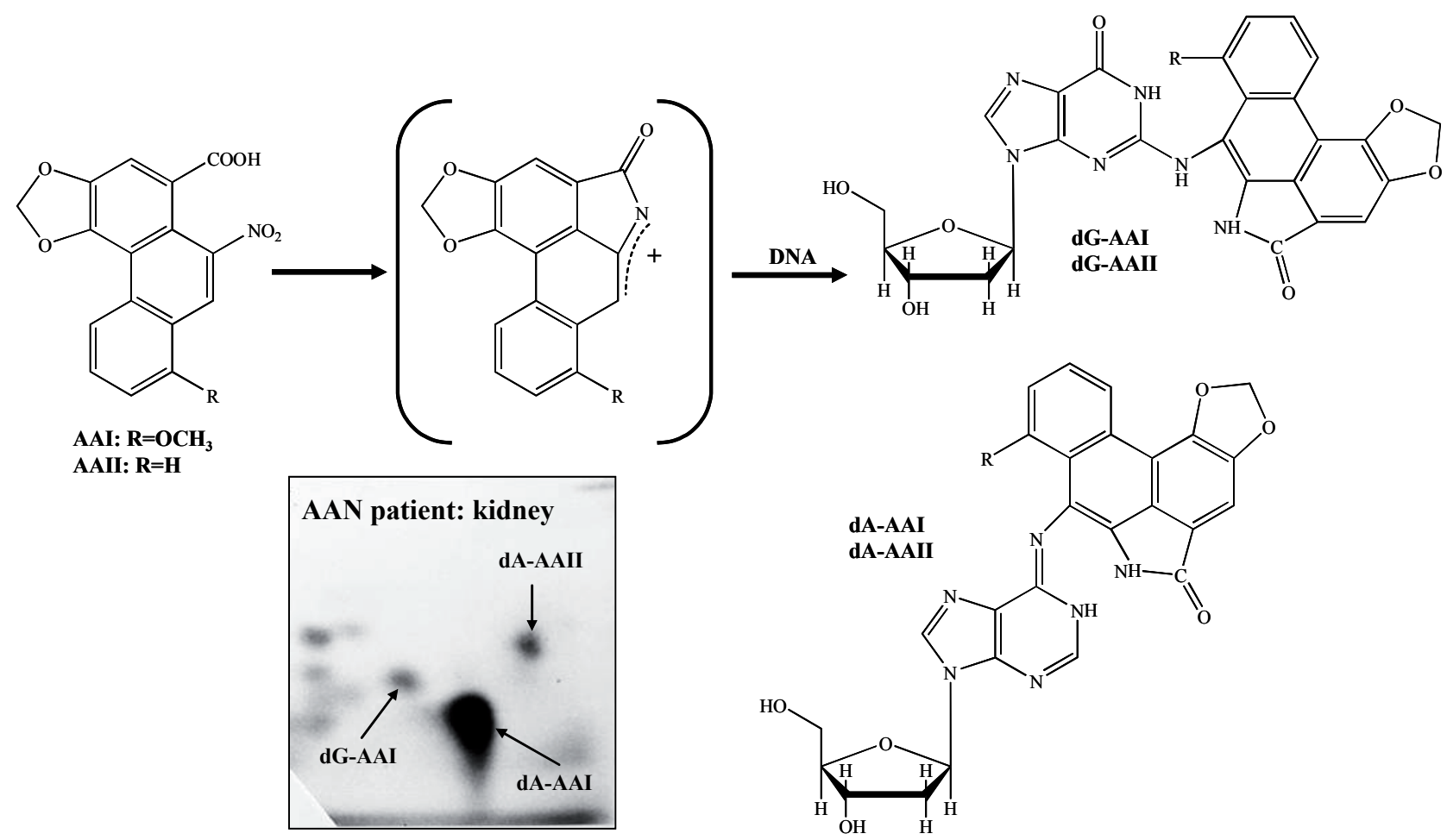

Fig. 2. Metabolic activation and DNA adduct formation of aristolochic acid I (AAI) and II (AAII); 7-(deoxyadenosin$N^{6}$-yl)aristolactam I or II (dA-AAI or dA-AAII), 7-(deoxyguanosin- $N^{2}$-yl)aristolactam I or II (dG-AAI or dG-AAII). Insert: Autoradiographic profile of DNA adducts detected by ${ }^{32} \mathrm{P}-$ postlabelling in renal DNA of a patient with aristolochic acid nephropathy (AAN).

sequence, herbal remedies containing species of the genus Aristolochia were recently classified as carcinogenic to humans (Group 1) by the International Agency for Research on Cancer (IARC) ${ }^{1,13}$.

It is also noteworthy that AA consumption may be a cause for the development of a similar type of kidney fibrosis with malignant transformation of the urothelium, the Balkan Endemic Nephropathy (BEN) ${ }^{14-17}$, which is widely found in certain areas of Romania, Croatia, Bosnia, Serbia and Bulgaria along the Danube river basin ${ }^{15,17,18}$. At least 25,000 individuals suffer from BEN or are suspected of having the disease, while the total number of people at risk in these countries may exceed 100,000. Although first described more than 50 years ago, the etiology of $\mathrm{BEN}$ remains unclear and is a matter of debate ${ }^{15,18}$. Over the last few years, evidence has accumulated that BEN is an environmental disease. Recent experimental data show that AA might be one of the most important etiologic factors in BEN and associated urothelial cancer ${ }^{16,18,19,20}$. AA exposure is associated with chronic dietary uptake of seeds of Aristolochia clematitis by the population living in BEN regions $\mathbf{s}^{14,16,21}$.

\section{Aristolochic Acid-mediated Renal Injury and Carcinogenesis}

The molecular mechanisms of AA-mediated renal injury and its role in urothelial-specific tumor development, are still a matter of debate and require further investigation. In this context, it is noteworthy that a case reported of AA-induced tumor development without renal injury ${ }^{22}$ suggests dissociation between AA-mediated nephrotoxicity and carcinogenicity. One recent study has indicated that AA seems to directly cause renal injury through activating mitochondrial permeability transition which was 
found recently in human renal tubular epithelial cells ${ }^{23}$. This suggestion, however, needs to be confirmed by further studies. Others suggest that metabolic activation of AA to species forming DNA adducts is not the only important step for AA-induced malignant transformation ${ }^{24,25}$ but that specific DNA damage also leads to cell-specific alterations at the protein transcriptional level and this might impair physiological processes ${ }^{26-29}$. In contrast to the suggestion that AA might be the direct cause of the interstitial nephropathy, metabolic activation of AA to species forming DNA adducts is an important step in AA-induced malignant transformation ${ }^{24,25}$. Indeed, the molecular mechanism of AA-induced carcinogenesis demonstrates strong association between DNA adduct formation, mutation pattern and tumor development ${ }^{24,30,31}$. The DNA adduct 7-(deoxyadenosin- $N^{6}$-yl)aristolactam I (dA-AAI) (Fig. 2), which is the most persistent AAadduct in target tissue, is a premutagenic lesion leading to $\mathrm{A}: \mathrm{T} \rightarrow \mathrm{A}: \mathrm{T}$ transversions in TP53 in DNA from urothelial tumours of AAN and BEN patients ${ }^{19,24,30,32}$.

\section{Metabolism of Aristolochic Acid} and Biotransformation Enzymes

A feature common to AAN and BEN is that not all individuals exposed to AA develop nephropathy or tumors. We have suggested earlier that one cause for these variable response may be individual differences in the activities of the enzymes catalyzing the biotransformation (detoxification and/or activation) of AA (for a summary $\mathrm{see}^{25}$ ). A large number of genes for the enzymes that metabolize toxins and carcinogens are known to exist in variant forms or show polymorphisms resulting in differing activities of the gene products. These genetic variations appear to be important determinants of cancer risk and other toxic effects of xenobiotics ${ }^{25}$.

The proposed activation and detoxification pathways of AAI are shown in Figure 3. AAI is activated by nitroreduction to $N$-hydroxyaristolactam I, a metabolite recently detected in the urine of AA-treated rats which confirms its formation during metabolism in vivo ${ }^{33}$. $\mathrm{N}$-Hydroxyaristolactam I can form a cyclic $\mathrm{N}$-acylnitrenium ion as the ultimate carcinogen binding to DNA. This leads to dA-AAI, the most persistent adduct in initiating car-

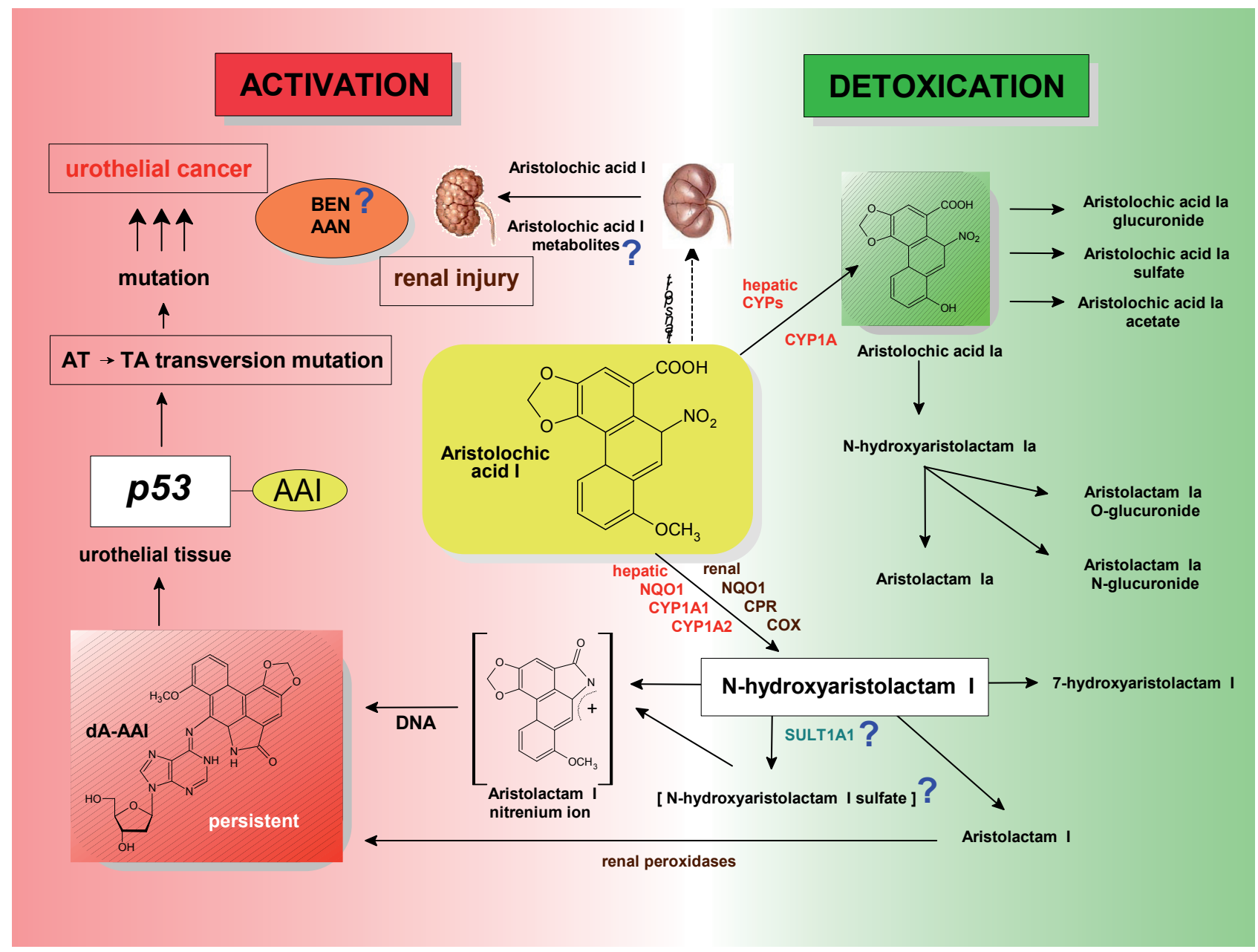

Fig. 3. Proposed pathway for metabolic activation and detoxication of aristolochic acid I (AAI), leading to renal injury and urothelial cancer. Aristolochic acid nephropathy (AAN); Balkan endemic nephropathy (BEN); 7-(deoxyadenosin- $\mathrm{N}^{6}$-yl)aristolactam I (dA-AAI); cytochrome P450 (CYP); NADPH:CYP reductase (CPR); cyclooxygenase (COX); sulfotransferase (SULT) (adapted from reference ${ }^{54}$ ). 
cinogenesis. The preference of AAI for reaction with the exocyclic amino group of DNA purine bases is unusual for nitroaromatic compounds since their ultimate carcinogenic species is a nitrenium ion whose major target site in DNA is the C-8 atom of guanine.

Enzymes activating AAI to species binding to DNA in vitro have been studied in detail ${ }^{25}$. Several in-vitro studies report that the most important human and rat enzyme to activate $\mathrm{AAI}$ in vitro in hepatic or renal cytosolic subcellular fractions, is $\mathrm{NAD}(\mathrm{P}) \mathrm{H}$ :quinone oxidoreductase (NQO1) ${ }^{34-36}$ followed by cytochrome P450 (CYP) 1A1/2 in hepatic microsomes ${ }^{37,38}$ and NADPH:CYP reductase (POR) in renal microsomes ${ }^{36,39}$. In addition, prostaglandin $\mathrm{H}$ synthase (cyclooxygenase, $\mathrm{COX}$ ) is able to bioactivate $\mathrm{AAI}^{36,40}$, which is highly expressed in urothelial tissue. It still remains to be confirmed however that isolated (purified) human NQO1 is actually able to activate AAI. Preliminary data shown in Table 1 indicate that human NQO1 is capable of activating AAI, much more efficiently than other enzymes (Stiborová et al., unpublished results). Such proof is of great importance as NQO1 polymorphism (the genotype $N Q O{ }^{*} 2 /{ }^{*} 2$ ) seems to predispose patients suffering from BEN to the development of urothelial malignancy $(\mathrm{OR}=13.75,95 \% \mathrm{CI} \text { 1.17-166.21 })^{41}$. Therefore, future work aims to confirm the predisposition of AAN patients to the development of cancer by NQO1polymorphism. Such studies might answer the question why AAI-induced cancer develops in some but not all BEN and/or AAN patients.

While most enzymes catalyzing the reductive activation of AAI in vitro have already been identified, it remains to be answered which of them actually participate in bioactivation in vivo. Additional factors such as route of administration, absorption, renal clearance and tissuespecific enzyme expression make it difficult to extrapolate from in vitro data to in-vivo situations ${ }^{25}$. Therefore such studies are required in the future.

The competing conversion of $N$-hydroxyaristolactam I to the corresponding 7-hydroxyaristolactam or its further reduction to aristolactam I should be considered a detoxification pathway as both metabolites have been found to be excreted. However, even though aristolactam I is not a direct DNA binding species, low levels of dA-AAI adduct, with highest levels in one of the target tissues (e.g. renal pelvis) were generated in rats treated with aristolactam $\mathrm{I}^{42}$. This is consistent with the formation of dA-AAI adduct by aristolactam I observed after in-vitro activation with different peroxidases such as COX-1 and/or COX-2 that are highly expressed in urothelial tissue ${ }^{43}$.

It is well known that conjugation reactions like acetylation and sulfonation catalyzed by phase II enzymes are important in the metabolic activation of carcinogenic nitroaromatics and aromatic amines. However, phase II conjugation reactions do not seem to play a role in AAI activation. In reality, it is still questionable whether enzymes capable of conjugating the proximate carcinogenic metabolite of AAI, $N$-hydroxyaristolactam I, are involved in AAI activation. While Meinl et al. ${ }^{31}$ demonstrated that expression of some human sulfotransferases (SULTs), par-
Table 1. Contribution of NQO1, CYP1A1/2, NADPH:CYP reductase and COX-1 enzymes to AAI activation.

\begin{tabular}{|l|c|}
\hline \multicolumn{1}{|c|}{ Enzyme } & $\begin{array}{c}\mathrm{K}_{0.5} \text { for AAI-DNA binding } \\
(\mu \mathrm{M})\end{array}$ \\
\hline NQO1 & $17 \pm 0.8$ \\
\hline CYP1A1 & $65 \pm 3.1$ \\
\hline CYP1A2 & $38 \pm 1.8$ \\
\hline NADPH:CYP reductase & $126 \pm 6.2$ \\
\hline COX-1 & $153 \pm 4.1$ \\
\hline
\end{tabular}

$\mathrm{K}_{0.5}$ - concentrations of AAI producing half of the maximal AAI binding to DNA

${ }^{a}$ Data shown are means \pm S.E.M. of three independent experiments. Data shown are based on results of our former studies for CYP1A1, 1A2, NADPH:CYP reductase and COX-1 ${ }^{37-40}$, while on unpublished results for NQO1.

ticularly SULT1A1, in bacterial and mammalian target cells enhances the mutagenic activity of AAI, the preliminary data from our laboratory produced ambiguous findings: on the one hand, we found that an increase in AAI-induced mutagenicity correlated with higher AAIDNA adduct levels in V79 cells transfected with human SULT1A1 (Glatt et al., unpublished data). On the other hand, further results suggested that SULTs in human hepatic and renal cytosols do not participate in AAI-DNA adduct formation in these subcellular systems (Stiborová et al., unpublished data). It seems more likely that instead, conjugation of $N$-hydroxyaristolactam I catalyzed by SULTs, the carboxy group in the peri position to the nitro group represents a unique example of an intra-molecular conjugation (acylation) leading to the formation of a cyclic hydroxamic acid ( $N$-hydroxylactam). In sum, the exact role of conjugation reactions and phase II enzymes in AAI activation awaits further investigations.

The oxidation of AAI to aristolochic acid Ia (AAIa) has been suggested to be a detoxification pathway of $\mathrm{AAI}^{5,25}$ (Fig. 3) as AAIa or its conjugates, the $O$-glucuronide, the $O$-acetate and the $O$-sulfate esters, are excreted in the urine ${ }^{33,44}$. AAIa is also reduced to $N$-hydroxyaristolactam Ia forming aristolactam Ia which together with its conjugates, the $N$ - and $O$-glucuronides, is excreted $^{33,44}$. Enzymatic reactions leading to aristolactam Ia and its metabolites seem to be solely a detoxification pathway because DNA adducts containing aristolactam Ia structure have, as yet, never been found.

In contrast to the enzymes activating $\mathrm{AAI}$ in vitro, those participating in AAI oxidation to AAIa both in vitro and in vivo have not been extensively studied so far. Recent studies in our laboratory have shown that human, rat and mouse hepatic CYP enzymes oxidize AAI into this detoxification metabolite AAIa ${ }^{25,45}$. Large-scale investigations in BEN patients on the role of genetic polymorphisms in some genes of phase I detoxification CYP enzymes revealed a possible risk for BEN (OR 2.41) in individuals 
carrying $C Y P 3 A 5^{*} 1$ allele G6989 ${ }^{41,46}$. Although we found that this CYP did not activate AAI to form DNA adducts (Stiborová et al., unpublished data), we do not know, whether this CYP species is involved in AAI detoxication.

Participation of mouse hepatic CYP enzymes in AAI oxidation to AAIa was recently confirmed by Xiao et $a .^{47}$, who published novel data on the enzymes detoxifying AAI. In this study, the authors used the HRN (Hepatic Cytochrome P450 Reductase Null) mouse model, previously shown to be suitable for examining hepatic versus extrahepatic xenobiotic metabolism in vivo ${ }^{48-51}$. For this reason, we have advocated this animal model for elucidating AA metabolism ${ }^{25}$. Xiao et al found that mouse hepatic CYPs detoxify AAI through demethylation to AAIa and in this way protect the kidney from AAI-induced injury ${ }^{47}$. The question, which of the mouse CYP enzymes is responsible for formation of AAIa requires further study. In-vitro experiments using hepatic mouse microsomes show that CYP1A enzymes generate $\mathrm{AAIa}^{47}$. but the mouse model used to evaluate the role of CYP1A in the formation of AAIa in vivo by inducing CYP1A via 3-methycholanthrene (MC), produced ambiguous results ${ }^{47,52}, \mathrm{MC}$ induces other enzymes beside CYP1A. Although treatment of mice with MC leads to decrease in AAI concentrations in the liver and kidney, no increase in AAIa concentrations was found in the liver, only in the kidney of mice treated with the higher dose of AAI ( $20 \mathrm{mg} / \mathrm{kg}$ body weight). An increase in AAIa excretion due to its conjugation with glucuronide, caused by induction of UDP-glucuronosyltransferase with MC, could occur. However as CYP1A enzymes also activate AAI to species forming DNA adducts ${ }^{25,36-38}$, the decrease in AAI in liver and kidney might also result from this reaction. Also, NQO1 which is also efficiently induced by MC, could contribute to decreased AAI levels in MC-treated mice.

More recently, we have increased our knowledge of the role of human hepatic CYP enzymes in AAI detoxification $^{45}$. The role of human hepatic CYP enzymes in AAI oxidation was investigated by modulation of this reaction by selective inhibitors of individual CYPs. We found most of the activation of AAI in human hepatic microsomes was attributable to CYP1A. In addition, human recombinant CYP1A1 and 1A2 were the most efficient CYPs for oxidizing AAI. Other CYPs such as CYP1B1, 2C8, $3 \mathrm{~A} 4$ as well as CYP2B6 with cytochrome $\mathrm{b}_{5}$, can also oxidize AAI but with efficiencies more than one order of magnitude lower than CYP1A ${ }^{45}$.

However, we found that under the anaerobic conditions, human CYP1A enzymes also reductively activate AAI to species forming DNA adducts ${ }^{37,38}$. Therefore, the oxygen concentration of tissues may affect the relative extent of AAI activation by nitroreduction and its detoxication by $O$-demethylation. In addition, orientation and moving of the AAI molecule to the active sites of CYP1A1 and 1A2 enzymes should also influence the pathways of AAI metabolism, namely, $O$-demethylation of AAI versus reduction of the nitro group of AAI. We plan to use the in-silico docking of AAI to the active sites of CYP1A1 and 1A2 using soft-soft (flexible) docking procedure $^{53}$ in further studies to elucidate the molecular mechanisms of oxidation and reduction of AAI by human CYP1A1 and 1A2.

The literature on the role of CYP1A in AAI detoxication $^{45,47}$ combined with the reports found for CYP1A - and NQO1-mediated AAI activation ${ }^{25,34,35,37,38}$, strongly support the hypothesis ${ }^{25}$ that a key factor determining the carcinogenic and nephrotoxic effects of AAI, is the balance of reductase activity such as NQO1, catalyzing the AAI-DNA adduct formation and enzymes such as CYPs which can both activate and detoxify AAI. Taking into account all the currently known data, we propose that the pathways of AAI metabolism are determined by: the binding affinity of AAI to CYP1A or NQO1 enzymes and their enzymatic turnover, as well as the balance between the efficiency of CYP1A in oxidizing and reducing AAI. To test this assumption and to complement earlier studies $^{25,45,47,52,54}$, we are currently investigating the formation of AAI-DNA adducts in HRN and CYPIA gene knock-out mouse models.

\section{CONCLUSIONS}

Although hepatic CYP enzymes have been shown to detoxify AAI in vitro and in vivo in mice, thus reducing AA1 nephrotoxicity, individual enzymes that may take part in the metabolisation ( activation and/or detoxification) of AAI in vivo have not been fully explored as yet. Their impact on AAI-mediated nephrotoxicity and carcinogenicity by evaluating inter-individual variations including genetic polymorphisms may be important to explaining individual susceptibility to AAI and to predict cancer risk among AAN and/or BEN patients. These are the subject of our ongoing investigations.

\section{ACKNOWLEDGEMENTS}

This work was supported by the Grant Agency of the Czech Republic (grant 303/09/0472) and Ministry of Education of the Czech Republic (grant MSM0021620808). Work at the Institute of Cancer Research is supported by Association for International Cancer Research (AICR) and Cancer Research UK.

\section{REFERENCES}

1. IARC (International Agency for Research on Cancer). Some traditional herbal medicines, some mycotoxins, naphthalene and styrene. IARC Monogr. Eval. Carcinog. Risks Hum. 2002; 82.

2. Vanherweghem JL, Depierreux M, Tielemans C, Abramowicz D, Dratwa M, Jadoul M, Richard C, Valdervelde D, Verbeelen D, Vanhaelen-Fastre B, Vanhaelen M. Rapidly progressive interstitial renal fibrosis in young women: association with slimming regimen including Chinese herbs. Lancet 1993; 341:387-91.

3. Vanhaelen M, Vanhaelen-Fastre R, But P, Vanherweghem JL. Identification of aristolochic acid in Chinese herbs. Lancet 1994; 343:174.

4. Schmeiser HH, Bieler CA, Wiessler M, van Ypersele de Strihou C, Cosyns JP. Detection of DNA adducts formed by aristolochic 
acid in renal tissue from patients with Chinese herbs nephropathy. Cancer Res 1996; 56:2025-28.

5. Arlt VM, Stiborova M, Schmeiser HH. Aristolochic acid as a probable human cancer hazard in herbal remedies: a review. Mutagenesis 2002; 17:265-77.

6. Debelle FD, Vanherweghem JL, Nortier JL. Aristolochic acid nephropathy: a worldwide problem. Kidney Int 2008; 74:158-69

7. Gillerot G, Jadoul M, Arlt VM, van Ypersele de Strihou C Schmeiser HH, But PHH, Bieler CA, Cosyns J-P. Aristolochic acid nephropathy in a Chinese patient: time to abandon the term "Chinese herbs nephropathy"? Am J Kidney Dis 2001; 38:E26.

8. Cosyns JP. Aristolochic acid and "Chinese herbs nephropathy": a review of the evidence to date. Drug Safety 2003; 26:33-48.

9. Nortier JL, Martinez MC, Schmeiser HH, Arlt VM, Bieler CA, Petřin M, Depierreux MF, De Pauw L, Abramowicz D, Vereerstraeten P, Vanherweghem JL. Urothelial carcinoma associated with the use of a Chinese herb (Aristolochia fangchi). N Engl J Med 2000; 342:1686-92.

10. Lord GM, Cook T, Arlt VM, Schmeiser HH, Williams G, Pusey CD. Urothelial malignant disease and Chinese herbal nephropathy. Lancet 2001; 358:1515-6.

11. Arlt VM, Alunni-Perret M, Quatrehomme G, Ohayon P, Albano L, Gaid H, Michiels JF, Meyrier A, Cassuto E, Wiessler M, Schmeiser HH, Cosyns J-P. Aristolochic acid (AA)-DNA adduct as marker of AA exposure and risk factor for AA nephropathy-associated cancer Int J Cancer 2004; 111: 977-80.

12. Gold LS, Slone TH. Aristolochic acid, an herbal carcinogen, sold on the Web after FDA alert. N Engl J Med 2003; 349:1576-7.

13. Grosse Y, Baan R, Straif K, Secretan B, El Ghissassi F, Bouvard V, Benbrahim-Tallaa L, Guha N, Galichet L, Cogliano V., WHO International Agency for Research on Cancer Monograph Working Group. A review of human carcinogens-Part A: pharmaceuticals. Lancet Oncol 2009; 10:13-4.

14. Ivic M. Etiology of endemic nephropathy. Lijec Vjesn 1969; 91:1273-81.

15. Tatu CA, Oren WH, Finkelman RB, Feder GL. The etiology of Balkan endemic nephropathy: still more questions than answers. Environ Health Perspect 1998; 106:689-700.

16. Arlt VM, Ferluga D, Stiborova M, Pfohl-Leszkowicz A, Vukelic M, Vdovic S, Schmeiser HH, Cosyns JP. Is aristolochic acid a risk factor for Balkan endemic nephropathy-associated urothelial cancer? Int J Cancer 2002: 101:500-2.

17. Stiborová M, Patočka J, Frei E, Schmeiser HH. Biochemistry and toxicological aspects of etiology of Balkan endemic nephropathy [in Czech]. Chem Listy 2005; 99:782-8.

18. Stefanovic V., Toncheva D, Atanasova S, Polenakovic M. Etiology of Balkan endemic nephropathy and associated urothelial cancer. Am J Nephrol 2006; 26:1-11.

19. Grollman AP, Shibutani S, Moriya M, Miller F, Wu L, Moll U, Suzuki N, Fernandes A, Rosenquist T, Medverec Z, Jakovina K, Brdar B, Slade N, Turesky R, Goodenough A K, Rieger R, Vukelic M, Jelakovic B. Aristolochic acid and the etiology of endemic (Balkan) nephropathy, Proc Natl Acad Sc USA 2007; 104:1212934.

20. Nedelko T, Arlt VM, Phillips DH, Hollstein M. TP53 mutation signature supports involvement of aristolochic acid in the aetiology of endemic nephropathy-associated tumours. Int J Cancer 2009; 124:987-90.

21. Hranjec T, Kovac A, Kos J, Mao W, Chen JJ, Grollman AP, Jelakovic B. Endemic nephropathy: the case for chronic poisoning by aristolochia. Croat Med J 2005; 46:116-25.

22. Nortier JL, Schmeiser HH, Martinez MCM, Arlt VM, Vervaet C, Garbar CH, Daelemans P, Vanherweghem JL. Invasive urothelial carcinoma after exposure to Chinese herbal medicine containing aristolochic acid may occur without severe renal failure. Nephrol Dial Transplant 2003; 18:426-28.

23. Qi X, Cai Y, Gong L, Liu L, Chen F, Xiao Y, Wu X, Li Y, Xue X, Ren J. Role of mitochondrial permeability transition in human renal tubuar epithelial cell death induced by aristolochic acid. Toxicol Appl Pharmacol 2007; 222:105-10.

24. Arlt VM, Stiborová M, vom Brocke J, Simoes ML, Lord GM,
Nortier JL, Hollstein M, Phillips DH, Schmeiser HH. Aristolochic acid mutagenesis: molecular clues to the etiology of Balkan endemic nephropathy-associated urothelial cancer. Carcinogensis 2007; 28: 2253-61

25. Stiborová M, Frei E, Arlt VM, Schmeiser HH. Metabolic activation of carcinogenic aristolochic acid, a risk factor for Balkan endemic nephropathy. Mutat Res 2008; 658:55-67.

26. Lebeau C, Arlt VM, Schmeiser HH, Boom A, Verroust PJ, Devuyst $\mathrm{O}$, Beauwens R. Aristolochic acid impedes endocytosis and induces DNA adducts in proximal tubule cells. Kidney Int 2001; 60:133242.

27. Lebeau C, Debelle FD, Arlt VM, Pozdzik A, De Prez EG, Phillips DH, Deschodt-Lanckman MM, Vanherweghem JL, Nortier JL. Early proximal tubule injury in experimental aristolochic acid nephropathy: functional and histological studies. Nephrol Dial Transplant 2005; 20:2321-32

28. Stemmer K, Ellinger-Ziegelbauer H, Ahr HJ, Dietrich DR Carcinogen-specific gene expression profiles in short-term treated Eker and wild-type rats indicative of pathways involved in renal tumorigenesis. Cancer Res 2007; 67:4052-68.

29. Simões ML, Hockley SL, Schwerdtle T, da Costa GG, Schmeiser HH, Phillips DH, Arlt VM. Gene expression profiles modulated by the human carcinogen aristolochic acid I in human cancer cells and their dependence on TP53. Toxicol Appl Pharmacol 2008; 232:86-98.

30. Schmeiser HH, Stiborovà M, Arlt VM. Chemical and molecular basis of the carcinogenicity of Aristolochia plants.Curr Opin Drug Discov Devel 2009; 12:141-8.

31. Meinl W, Pabel U, Osterloh-Quitroz H, Hengstler JG, Glatt H. Human sulphotransferases are involved in the activation of aristolochic acids and are expressed in renal target tissue. Int J Cancer 2006; 118:1090-7.

32. Lord GM, Hollstein M, Arlt VM, Roufosse C, Pusey CD, Cook T, Schmeiser HH. DNA adducts and $p 53$ mutations in a patient with aristolochic acid-associated nephropathy. Am J Kidney Dis 2004; 43:e11-17.

33. Chan W, Luo H-B, Zheng Y, Cheng Y-K, Cai Z. Investigation of the metabolism and reductive activation of carcinogenic aristolochic acid in rats, Drug Metab Dispos 2007; 35:866-74.

34. Stiborová M, Frei E, Sopko B, Wiessler M, Schmeiser HH Carcinogenic aristolochic acids upon activation by DT-diaphorase form adducts found in DNA of patients with Chinese herbs nephropathy. Carcinogenesis 2002; 23:617-25.

35. Stiborová M, Frei E, Sopko B, Sopková K, Marková V, Laňková M, Kumstýřová T, Wiessler M, Schmeiser HH. Human cytosolic enzymes involved in the metabolic activation of carcinogenic aristolochic acid: evidence for reductive activation by human NAD $(P)$ H:quinone oxidoreductase. Carcinogenesis 2003; 24:1695-703.

36. Stiborová M, Frei E, Hodek P, Wiessler M, Schmeiser HH. Human hepatic and renal microsomes, cytochromes P450 1A1/2, NADPH:cytochrome $\mathrm{P} 450$ reductase and prostaglandin $\mathrm{H}$ synthase mediate the formation of aristolochic acid-DNA adducts found in patients with urothelial cancer. Int J Cancer 2005; 113:189-97.

37. Stiborová M, Frei E, Wiessler M, Schmeiser HH. Human enzymes involved in the metabolic activation of carcinogenic aristolochic acids: evidence for reductive activation by cytochrome P450 1A1 and 1A2. Chem Res Toxicol 2001; 14:1128-37.

38. Stiborová M, Sopko B, Hodek P, Frei E, Schmeiser HH, Hudeček J. The binding of aristolochic acid I to the active site of human cytochromes P450 1A1 and 1A2 explains their potential to reductively activate this human carcinogen. Cancer Lett 2005; 229:193-204.

39. Stiborová M, Hájek M, Frei E, Schmeiser HH. Carcinogenic and nephrotoxic alkaloids aristolochic acids upon activation by NADPH:cytochrome P450 reductase form adducts found in DNA of patients with Chinese herbs nephropathy. Gen Physiol Biophys 2001; 20:375-92.

40. Stiborová M, Frei E, Breuer A, Wiessler M, Schmeiser HH Evidence for reductive activation of carcinogenic aristolochic acids by prostaglandin $\mathrm{H}$ synthase - ${ }^{32} \mathrm{P}$-postlabeling analysis of DNA adduct formation. Mutat Res 2001; 493:149-60.

41. Toncheva D I, von Ahsen N, Atanasova SY, Dimitrov TG, 
Armstrong VM, Oellerich M. Identification of NQO1 and GSTs genotype frequencies in Bulgarian patients with Balkan endemic nephropathy. J Nephrol 2004; 17:384-89.

42. Dong H, Suzuki N, Torres MC, Bonala RR, Johnson F, Grollman AP, Shibutan S. Quantitative determination of aristolochic acidderived DNA adducts in rats using ${ }^{32} \mathrm{P}$-postlabeling/polyacrylamide gel electrophoresis analysis. Drug Metab Dispos 2006; 34:1122-27.

43. Stiborová M, Frei E, Breuer A, Bieler CA, Schmeiser HH Aristolactam I a metabolite of aristolochic acid I upon activation forms an adduct found in DNA of patients with Chinese herbs nephropathy. Exp Toxic Pathol 1999: 51:421-27.

44. Chan W, Cu L, Xu G, Cai Z. Study of the phase I and phase II metabolism of nephrotoxin aristolochic acid by liquid chromatography/tandem mass spectrometry, Rapid Commun. Mass Spectrom 2006; 20:1755-60.

45. Šístková J, Hudeček J, Hodek P, Frei E, Schmeiser HH, Stiborová M. Human cytochromes P450 1A1 and 1A2 participate in detoxication of carcinogenic aristolochic acid. Neuro Endocrinol Lett 2008; 29:733-7.

46. Toncheva D. Genetic studies in BEN and associated urothelial cancers. Coll. Antropol 2006; 30Suppl 1:34.

47. Xiao Y, Ge M, Xue X, Wang H, Wu X, Li L, Liu L, Qi X, Zhang Y, Li Y, Xie T, Gu J, Ren J. Detoxication role of hepatic cytochrome $\mathrm{P} 450$ s in the kidney toxicity induced by aristolochic acid. Kidney Int 2008; 73:1231-9.

48. Arlt VM, Stiborova M, Henderson CJ, Osborne MR, Bieler CA, Frei E, Martinek V, Sopko B, Wolf CR, Schmeiser HH, Phillips DH Environmental pollutant and potent mutagen 3-nitrobenzanthrone forms DNA adducts after reduction by $\mathrm{NAD}(\mathrm{P}) \mathrm{H}$ :quinone oxidore- ductase and conjugation by acetyltransferases and sulfotransferases in human hepatic cytosols. Cancer Res 2005; 65:2644-52.

49. Arlt VM, Henderson CJ, Wolf CR, Schmeiser HH, Phillips DH, Stiborova M. Bioactivation of 3-aminobenzanthrone, a human metabolite of the environmental pollutant 3-nitrobenzanthrone: evidence for DNA adduct formation mediated by cytochrome P450 enzymes and peroxidases. Cancer Lett 2006; 234:220-31.

50. Arlt VM, Stiborová M, Henderson CJ, Thiemann M, Frei E, Aimová D, Singhs R, da Costa GG, Schmitz OJ, Farmer PB, Wolf $\mathrm{CR}$, Phillips DH. Metabolic activation of benzo[a]pyrene in vitro by hepatic cytochrome P450 contrasts with detoxification in vivo: experiments with hepatic cytochrome $\mathrm{P} 450$ reductase null mice. Carcinogenesis 2008; 29:656-65.

51. Stiborová M, Arlt VM, Henderson CJ, Wolf CR, Kotrbová V, Moserová M, Hudeček J, Phillips DH, Frei E. Role of hepatic cytochromes $\mathrm{P} 450$ in bioactivation of the anticancer drug ellipticine: studies with the hepatic NADPH:cytochrome P450 reductase null mouse. Toxicol Appl Pharmacol 2008; 226:318-27.

52. Xue X, Xiao Y, Zhu H, Wang H, Liu Y, Xie T, Ren J. Induction of P450 1A by 3-methylcholanthrene protects mice from aristolochic acid-I-induced acute renal injury. Nephrol Dial Transplant 2008; 23:3074-81

53. Reynisson J, Stiborová M, Martínek V, Gamboa da Costa G, Phillips DH, Arlt VM. Mutagenic potential of nitrenium ions of nitrobenzanthrones: correlation between theory and experiment. Environm Mol Mutagenesis 2008; 49:659-67.

54. Stiborová M, Frei E, Schmeiser HH. Biotransformation enzymes in development of renal injury and urothelial cancer cause by aristolochic acid. Kidney Int 2008; 73:1209-11. 
